\title{
К ГЕНЕЗИСУ КРИТИКИ ИСТОРИЦИСТСКИХ МЕТОДОЛОГЕМ
}

\section{В.А. Черниенко}

Пресловутое «состояние постмодерна» характеризуется мозаичностью социокультурной практики и, как следствие, плюрализмом в идейной сфере. Такой плюрализм служит основанием для отрицания единой определяющей основы общества, для взгляда на историю как на поток случайных событий, следовательно, для отказа от объективных законов развития общества. В социальной философии происходит смещение интереса современных исследователей в сторону анализа феноменов «слепых», ненаправленных колебаний социальной жизни - феноменов, к которым было приковано внимание мыслителей прошлого (например, $\mathrm{KoH}_{-}$ фуция, Сенеки, Макиавелли). Поздние теории приверженцев ненаправленного хода истории (например, П. Сорокина, О. Шпенглера, А. Тойнби, С. Хантинтона) претендуют быть более научными, чем, как полагали их авторы, спекулятивные теории «тенденциозных законодателей» (например, Платона, Г. Гегеля, К. Маркса).

Однако и сегодня остается нерешенной центральная проблема философии истории - проблема существования всемирной истории человечества, проблема механизмов и фаз становления и перспектив дальнейшего развития человечества как целостного интегративного образования исторической жизни. В этом «вечном» философском споре участвуют различные методологические мотивы- методологемы. При этом необходимо учитывать, что одни из них лучше других соответствуют реальной истории и этим претендуют на статус науки, упраздняющей (снимающей) историцистский дискурс ${ }^{1}$.

\footnotetext{
${ }^{1} \mathrm{~B}$ данном споре первостепенное значение имеют, на наш взгляд, следующие работы: К.Маркса «Тезисы о Фейербахе» (1845), Ф.Энгельса «Анти-Дюринг» (18761878), К. Поппера «Открытое общество и его враги» (1945), М. Корнфорта «Открытая философия и открытое общество» (1968), Ф.Фукуямы «Конец истории?» (1989),
}

Актуальні проблеми духовності

(Відп. ред.: Я.В. Шрамко)

Кривий Ріг (2005), 338-346 
Для упорядочения многообразных способов связи того или иного социально-философского учения с методологией науки и возможности учета методологического сходства и тенденции к взаимной ассимиляции различных социально-философских направлений целесообразно вычленить ряд ключевых методологических подходов, образующих в настоящее время систему социально-философского знания в виде некоего иерархически построенного целого, состоящего из элементов разной степени общности. Речь идет о понятии «исследовательская программа» или «научная программа».

«Исследовательская программа - это философская программа развития науки. Но она не тождественна тому или иному философскому направлению, ибо не всякое философское направление служит базой развития научных теорий, иногда ряд философских ориентаций объединяются для формирования одной исследовательской программы» [3, с. 216]. Исследовательская программа претендует на универсальное толкование всего существующего. Система принципов, формируемая программой, носит поэтому всеобщий характер. (Как правило, всеобщность провозглашается, но не демонстрируется, поэтому такие программы больше являются идеологией, нежели наукой.)

В социально-философском знании генетически первой была натуралистическая исследовательская программа, которая формировала методологические нормативы социального знания по образу естественных наук. Открытие культуры как особой реальности конституировало культурцентристскую исследовательскую программу. Взгляд на историю, как на практическую деятельность людей, детерминируемую экономикой, технологией, техникой характеризует марксистскую исследовательскую программу, претендующую на преодоление крайностей натурализма и культурцентризма. Попытки создания иных программ, как правило, характеризуются тяготением к одной из названных. Предпринимались попытки создания «единой» исследовательской программы-нечто вроде синтеза прежних, однако идея такой «интерференции» оказалась нежизнеспособной.

Высказывается возможность создания еще одной исследовательской программы - экологической. Экологическая программа выражает тенденцию развития знания - синтез общественных, естественных, математических и технических наук. Эта программа требует превращения науки из универсальной производительной силы в универсальную социально-преобразующую силу. Для нас очевидно, что данная программа является дальнейшим развитием марксистской программы.

В.Л.Иноземцева «За пределами экономического общества» (1998), М. Кастельса «Информационная эпоха: экономика, общество и культура» (2000). 
В рамках исследовательских программ особое место занимает теоретико-методологическая ориентация, которую можно определить как бинарную оппозицию «социологического реализма» и «социологического номинализма». Согласно социологическому реализму общество в целом, равно как и отдельные социальные институты, выступает в качестве самостоятельной сущности - «субстанции», несводимой к эмпирически фиксируемому взаимодействию отдельных индивидов. Социологический номинализм отказывается признавать за реальность как общество в целом, так и отдельные социальные институты, считая, что ею обладают лишь индивиды.

Здесь реализм и номинализм выступают в качестве эвристик. Несмотря на довольно абстрактную форму этих эвристик, выбор той или иной из них существенно предопределяет ход исследования - эвристика говорит нам, что может служить ответом на задачу, а что мы отказываемся принимать как таковой. Тем самым сужается круг поисков возможных решений.

Обе эвристики уязвимы как в теоретическом, так и в морально-нравственном отношении. Попытки их синтеза или примирения малоэффективны. Социальное к индивидуальному, и наоборот, без остатка не сводится. Поэтому в рамках экологической (гуманистической) исследовательской программы производится активный поиск чего-то «третьего», равно принадлежащего индивидам и обществу, в котором их изначальная противоположность была бы снята. На роль такого «третьего» - «клеточки» социальной субстанции - предлагаются различные интерпретации человеческих взаимодействий, имманентно присущих «индивидам»и «обществу».

Однако гносеолого-методологический прорыв в этом направлении еще не наступил. Необходимо помнить об онтологической несамодостаточности (вторичности) социального действия, не способного существовать автономно. На это уже указывал Гегель в «Философии права» (1821), подчеркивая, что человек есть самоцель, но только через опосредование другими индивидуумами, целым. Поэтому, эвристика социологического реализма (ее умеренный вариант) и сегодня является доминирующей при анализе общественных явлений.

Спускаясь по иерархической лестнице любой социально-философской исследовательской программы, обнаруживаешь основополагающие гносеологические принципы, обладающие равной методологической значимостью для различных (диахронных, синхронных) философских направлений. Речь идет о принципах историзма, аисторизма, историцизма и принципах детерминизма, индетерминизма. Так, например, «история»-это последовательная смена состояний любого объекта, способного развиваться во времени. 
Социальная философия базируется на предельно общем представлении об истории - «философии истории». История в этом случае выступает и как способ бытия объекта познания, и как ведущий принцип (метод) познания, программной установкой которого служит создание единой исторической картины мира.

Идея мира-как-истории восходит к глубокой древности, где она (история) выступает в различных формах: то топчется на месте, то возвращается циклически к одним и тем же состояниям, то представлена в виде непрерывной линии-стрелы. Ясно, что неявной предпосылкой конфигурации мира-как-истории выступает образ «социального времени». Именно конфигурация социального времени задает картину движения социума.

Разное понимание социального времени позволяет свести многообразные способы описания движения социумов к четырем основным подходам в рамках социологического реализма и номинализма.

Социологический реализм:

1) парадигма прогрессивно-поступательного типа движения социума: образ социального времени - стрела; мир-как-единая, непрерывная, целенаправленная история, характеризует онтологию представителей этого типа, причем независимо от того, являются ли они теистами или атеистами (например, Августин, Аквинат, Кант, Гегель); обоснование всех социальных явлений - мистический, динамический или стохастический детерминизм; методологема - историцизм, выступающий теорией движущей силы всех перемен, признающий, что изменения управляются неизменным законом; «феноменология духа» этого мировоззрения выступает как линейная, непрерывная, всевозрастающая хронология разума; ${ }^{2}$

2) парадигма чисто циклического типа движения социума: образ социального времени - круг (замкнутый цикл); циклическое изменение мира в целом (природы, общества и мышления) есть плюралистическая онтология морфологии мировой истории (сторонники, например, Гераклит, Эмпедокл, О. Шпенглер, Л. Гумилев), что элиминирует идею единой мировой истории; обоснование всех социальных явлений - динамический детерминизм; методологема - историцизм; «феноменология духа» этого мировоззрения выступает как эпистемологическая несовместимость и несоизмеримость различных культур (см., например, [9]);

3) парадигма волнообразного типа движения социума: образ социального времени - волна; волнообразное (синусоидальное) развитие социума представляет определенную направленность (тенденцию) к усложнению социальных связей и отношений посредством сменяющих друг друга

\footnotetext{
${ }^{2}$ Традиционно марксизм отождествляется вульгаризаторами с историцизмом, однако, на наш взгляд, у Маркса «историцизм» преодолевается «историзмом», «царство необходимости» - «царством свободы».
} 
волн изменений различных природы и масштаба (сторонники, например, Ф. Бродель, И. Валлерстайн, А. Шлезингер, П. Сорокин, Н. Кондратьев); переход от одной фазы развития общества к другой актуализируется точками «бифуркации», где нарушается предопределенность развития социума; обоснование всех социальных явлений - стохастический детерминизм; методологема - синергизм (см., например, [4]), доктрина бесцельных исторических флуктуаций; «феноменология духа» этого мировоззрения выступает как включенность индивида в проблемное поле своей эпохи, что в широком смысле также предполагает возможную эпистемологическую несовместимость и несоизмеримость.

\section{Социологический номинализм:}

4) парадигма - аисторизм; образ социального времени - ризома; философская ориентация - постмодернизм; «ситуация постмодерна» - недоверие к метанарративам (метарассказам, метаисториям, метадискурсам), которые выступают в качестве ведущих философских принципов Нового времени (например, гегелевская диалектика духа, идея прогресса, общечеловеческая эмансипация через всеобее просвещение, исторический детерминизм и т.д.); обоснование всех социальных явлений - индетерминизм, который получает обоснование в отрицании принципа «иерархии сил» (природной, социальной и мыслительной действительности), характерного для прежних мировоззрений; методологема - деконструктивизм (см., например, [1], [2]); ведущим гносеологическим принципом здесь является принцип «нониерархии», лежащий в основе структурирования любых постмодернистских текстов; теория познания - гносеологический плюрализм (анархизм); сторонники этого подхода - Ж. Деррида, Ж. Делез, Ф. Гваттари, Ж.-Ф.Лиотар и др.

Сравнивая эвристический потенциал социально-философских методологем необходимо учитывать, что наши концептуальные представления коррелируют с социальными и культурными условиями, в которых они создаются. Матрица социального бытия неявно препостулирует матрицу познания мира. Хотя эта согласованность не является жесткой и однозначной на индивидуальном уровне, на социальном уровне она очевидна. Поэтому и идея истории, какие бы формы она не приняла (от монизма до плюрализма), является, в известном отношении, «калькой» особенностей общественного бытия (от авторитаризма до демократии).

Так, западно-европейский мир пришел в интенсивное движение с победой Реформации. Обозначилась смена методологем: теизм-пантеизмдеизм-атеизм. Успехи буржуазных революций XVI-XVIII вв. усилили секуляризацию общества. Разложение феодализма и зарождение капитализма, образование наций, систематическое развитие культурных связей, углубляющееся международное разделение труда, образование мирового 
рынка ознаменовало начало всемирной истории. Обозначилась тенденция обобществления, коммунизации человечества в сфере обмирщения ключевых общественных отношений, следовательно, прогрессивно-поступательной десакрализации и демонополизации разделенного труда. Это движение увлекло и теоретиков.

Философия стала терять метатеоретический статус в освоении мира. Многовековая, не всегда оправданная амбициозная претензия философов спекулятивно, догматически эксплицировать априорные универсальные принципы, общеобязательные к исполнению всеми сферами знания, нашла свое отражение в таких образах философии, как «мать наук», «наука наук», «метанаука», «царица наук», «универсальная наука», «абсолютная наука». Такой абсолютный (беспредпосылочный) статус философии в разные времена выполнял разные социальные роли: от прогрессивной до реакционной.

Особенность философского мировоззрения заключается в том, что в нем впервые было выработано понятие об универсальной связи как безликой, абстрактной, господствующей в мире и в самом обществе Необходимости или Законе (идея «Абсолютной Справедливости», например: Дхарма - в древнеиндийской философии; Дао - в древнекитайской философии; Логос - в древнегреческой философии; гегелевская Абсолютная Идея и т.д. и т.п.). В философии абстракции, т.е. продукты чистой мысли, принимаются за вещи. Философия-это особое отчуждение, а именно, абсолютизация, онтологизация, гипостазирование всеохватывающей абстракции. Поэтому любая «философия в старом смысле слова» (метафизика-как-метанаука) есть идеализм, есть онаученная, логически систематизированная религия, а религия есть самосознание человека, который или еще не обрел себя, или уже снова себя потерял (заострим: «сон разума рождает чудовищ»). Поэтому сознательная, научная критика начинается с критики мифа и религии, и далее оттачивается в борьбе с философскими предрассудками и модной философской реакцией.

Критика оружием и оружие критики («критика критических критик») во всемирно-историческом масштабе есть объективное движение знания от «абстрактной всеобщности» к «конкретной всеобщности», т.е. есть диалектическое снятие мифа-религии-метафизики наукой (важно понимать, что этот процесс асимптотический: сама философия как культура сомнения в существующей, наличной логике возможна только в маргинальных, переходных моментах познания, т.е. философия есть лишь там, где есть особый спор, где осознается проблема тождества мышления и бытия, где знание ставшее догмой подвергается сомнению).

Итак существуют, бытийствуют, действуют не Абсолютные Законы, управляющие всеми процессами, совершающимися в природе, обществе и 
познании, а конкретные законы, управляющие различными сферами природы, общества и познания. «Абсолютные Законы» (философские категории) представляют собой лишь абстракции, необходимые теоретическому мышлению, но не образующие конкретного содержания процесса практического овладения законами природы, общества и познания. Адекватное оперирование категориями означает культуру мышления.

Конкретные социальные законы имеют объективный характер, но не по отношению к самим людям, продуктом деятельности которых они выступают, а по отношению к их сознанию. Осознав эти законы, люди могут воздействовать на них, ограничивать проявление одних и давать дорогу другим: это зависит, например, от реального соотношения сил прогресса и реакции. Главное здесь понять, что исторические изменения не происходят сами по себе-самотеком, а опосредованы борьбой социальных партий; в конечном счете побеждает прогрессивная партия, прогрессивная тенденция (философская рефлексия истории: циклически-волновая модель с восходящим трендом). Осознанная, т.е. прогнозируемая деятельность является здесь культурно-революционным фактором. Более того, объективное свойство роста знания таково, что исторические предсказания на его основе влияют на предсказанные события, искажая их действительный ход, а порой и полностью их элиминируя. Но переход от традиции к инновации в истории не так прост. В работе «Восемнадцатое брюмера Луи Бонапарта» (1852) Маркс писал (см. [6, с. 422]), что люди сами делают свою историю, но они ее делают не так, как им вздумается, при обстоятельствах, которые не сами они выбрали, а которые непосредственно имеются налицо, даны им и перешли от прошлого; традиции всех мертвых поколений тяготеют, как кошмар, над умами живых. Отряхнуть этот прах (пережитки) непросто. Дело в методе.

Метод лишь тогда согласуется с предметом, когда позволяет эффективно (в пределе оптимально) изменять предмет. Так, основоположники марксизма утверждали, что они знают только одну-единственную науку (метод), науку истории. Действительно, историческое мышление, как момент мышления вообще, позволяет наиболее адекватно объяснить согласование форм мышления с формами действительности, т.е. снять проблему основного вопроса философии-как-науки, проблему вопроса об истине. «Исторический метод» предписывает исследователю при познании вещей и явлений исходить из их становления, т.е. возникновения и развития. При этом выявляется логика (без панлогизма), закон развития (в обществе: закон-тенденция), на основании которого возможно не только объяснить прошлое предмета исследования, но и прогнозировать альтернативные тенденции дальнейшей его эволюции, следовательно, осознанно изменять предмет. И здесь дело даже не в масштабах прогнозов и изменений, а в новом качестве субъекта истории, в исторической ступени его 
рефлексии, его свободы. Так, материалистическое понимание истории как ступень познания упраздняет «метаисторического кукловода».

Опредмечивая мир трудом, человек постигает законы, логику мира: например, мир есть вечно движущаяся материя. Познанные, осознанные законы бытия становятся законами разума, логическими законами. Есть и особенная логика рефлексии форм общественной жизни. Научный анализ этих форм, как писал Маркс в «Капитале» (см. [7, с.85-86]), вообще избирает путь, противоположный их действительному развитию; анализ начинается post festum (задним числом), т.е. исходит из готовых результатов процесса развития; формы успевают уже приобрести прочность естественных форм общественной жизни, прежде чем люди сделают первую попытку дать себе отчет не в историческом характере этих форм,- последние уже, наоборот, приобрели для них характер непреложности, а лишь в их содержании; это-общественно значимые, следовательно, объективные мыслительные формы.

Это старая история: вначале всегда из-за содержания мышления не обращают внимания на его форму. Ранее на эту особенность (post festum) познания форм общественной жизни метафорически указал Гегель: «Сова Минервы вылетает в сумерки». По-видимому, «сумерки истории» (стихийная глобализация общественных отношений при капитализме) позволили Марксу сформулировать «Тезисы о Фейербахе» (1845), названные $\Phi . Э$ нгельсом «гениальным зародышем нового мировоззрения» (уточним: научного мировоззрения - самосознания человечества). На наш взгляд, эти «тезисы» de jure упраздняют (снимают) историцизм и знаменуют начало эры оптимально направляемой истории.

Марксизм вообще есть принципиальный этап в деле теоретической и практической эмансипации общества, а именно, исторического снятия монополизации и сакрализации разделенного труда. В марксизме главное - возврат сущности человека посредством упразднения отношения «разделенный труд». Здесь «сущность человека»- совокупность всех общественных отношений, т.е. чтобы познать человека, нужно познать всю его историю, мировую историю (весь ансамбль отношений), которая сжато, идеально содержится в науке истории (шире: диалектике). В этой науке абстрактно выражен весь совокупный разделенный труд. Тот, кто в состоянии эту науку присвоить, тот и вернет себе человеческую сущность и этим преодолеет отчуждение, разделение труда. Эта предельно абстрактная, обобщенная наука является разносторонне развитой производительной силой и только разносторонне развитые индивиды могут ее присвоить, следовательно, превратить в свою свободную самодеятельность. Прав был В.И.Ленин, полагая (см. «Задачи союзов молодежи» (1920), $[5$, с. 183]), что коммунистом стать можно лишь тогда, когда обогатишь свою память знанием всех тех богатств, которые выработало человече- 
ство (речь идет о своего рода десакрализации и демонополизации труда теоретика, и теоретической эмансипации общества). К этому приводит закон капитализма - абсолютное развитие вещественных и субъективных производительных сил. А то, что это возможно демонстрирует, например, «коммунизация» капитализма Финляндии (см., например, [8]): всеобщее управление, учет и контроль; всеобщая открытость информации; всеобщая инновационная деятельность; всеобщее перманентное образование и т.п. «Современный» коммунизм - не идеал, не цель, а техническое средство для достижения цели - всестороннего развития индивидов.

Резюмируя сказанное, можно отметить, что философия истории освобождается от умозрительного конструирования целостной всеобщей истории с необходимой для нее телеологией. Но если это так, то вряд ли сегодня возможна традиционная философия истории. Она как пережиток должна быть de facto упразднена. Потребность же в метадискурсах как жанрах «опережающего отражения», по-видимому, останется.

\section{1 Литература}

[1] Илъин И.П. Постструктурализм. Деконструктивизм. Постмодернизм. - М.: Интрада, 1996.

[2] Ильин И.П. Постмодернизм от истоков до конца столетия: эволюция научного мифа. - М.: Интрада, 1998.

[3] Исторический материализм как методология познания и преобразования общественной жизни. - М.: Наука, 1987.

[4] Капища С.П., Курдюмов С.П., Малинецкий Г.Г. Синергетика и прогнозы будущего. 2-е изд. - М.: Эдиториал УРСС, 2001.

[5] Ленин В.И. Избранные произведения. В 4-х т. Т. 4.-2-е изд.-М.: Политиздат, 1988.

[6] Маркс К., Энгельс Ф. Избранные произведения. В 3-х т. Т. 1.-М.: Политиздат, 1980.

[7] Маркс К. и Энгельс Ф. Сочинения. Т. 23. - М.: Политиздат, 1960.

[8] Химанен П., Кастельс М. Информационное общество и государство благосостояния: Финская модель.: Пер. с англ. - М.: Логос, 2002.

[9] IIпенглер О. Закат Европы. Том I, Том II. - М.: Мысль, 1993-1998. 